\title{
Sacroiliitis-like Changes in 2 Patients with Spina Bifida
}

JONATHAN CHAN, MD, FRCPC, Spondylitis Program, Toronto Western Hospital, and Division of Rheumatology, Department of Medicine, University of Toronto; ISMAIL SARI, MD, Spondylitis Program, Toronto Western Hospital, and Division of Rheumatology, Department of Medicine, University of Toronto, Toronto, Ontario, Canada, and Department of Rheumatology, Dokuz Eylul University School of Medicine, Izmir, Turkey; NIGIL HAROON, MD, $\mathrm{PhD}$, DM, Spondylitis Program, Toronto Western Hospital, and Division of Rheumatology, Department of Medicine, University of Toronto, Toronto, Ontario, Canada. Address correspondence to Dr. N. Haroon, Toronto Western Hospital, 399 Bathurst St., 1E-425, Toronto, Ontario M5T 2S8, Canada. E-mail: Nigil.Haroon@uhn.ca. J Rheumatol 2016;43:673; doi:10.3899/jrheum.150980

The hallmark joints affected in ankylosing spondylitis are the sacroiliac (SI) joints ${ }^{1}$. In the absence of infection, fracture, and malignancy, significant erosions and sclerosis of the SI joints are thought to be highly characteristic for ankylosing spondylitis $^{2}$. We identified 2 patients referred for SI joint changes compatible with sacroiliitis on computed tomography scan who had a history of spina bifida but were not considered to have axial spondyloarthritis. To our knowledge there is no relationship between these 2 diseases.

The first patient (Figure 1A and 1B) was a 42-year-old female who developed lower back discomfort, at age 20 years, with purely mechanical features that did not require any treatment. At age 39 she developed painless swelling in both knees that was not responsive to cortisone injections or nonsteroidal antiinflammatory drugs.

The second patient (Figure 1C) was a 47-year-old female who developed back pain with mechanical features at age 41 years after a fall from standing height. No radiograph was available for this patient. Neither patient had clinical features in keeping with spondyloarthritis and both were negative for HLA-B27 and acute-phase reactants.

We propose that a high degree of physical loading of the SI joints may result in sacroiliitis-like changes and should be considered on the differential diagnosis. These findings should be investigated on a larger scale to confirm whether a relationship truly exists. We propose that in predisposed individuals, lower degrees of physical loading may play a role in the pathogenesis of sacroiliitis by affecting the synovio-entheseal complex ${ }^{3}$.

\section{REFERENCES}

1. Braun J, Sieper J. Ankylosing spondylitis. Lancet 2007;369:1379-90.

2. Aydingoz U, Yildiz AE, Ozdemir ZM, Yildirim SA, Erkus F, Ergen FB. A critical overview of the imaging arm of the ASAS criteria for diagnosing axial spondyloarthritis: what the radiologist should know. Diagn Interv Radiol 2012;18:555-65.

3. McGonagle D, Aydin SZ, Tan AL. The synovio-entheseal complex and its role in tendon and capsular associated inflammation. J Rheumatol Suppl. 2012 Jul;89:11-4.

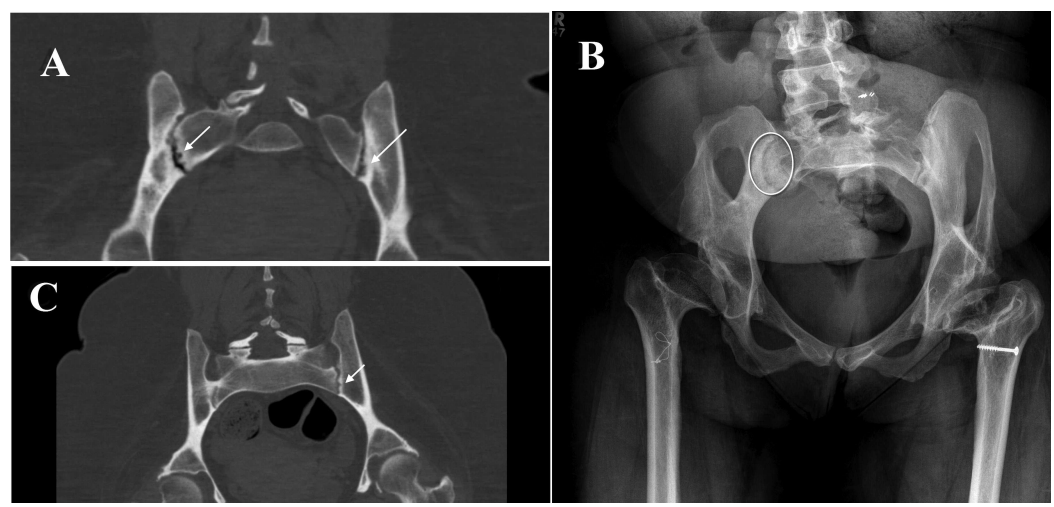

Figure 1. A. Both SI joints demonstrate numerous erosions (arrows) on CT scan. A significant amount of sclerosis is also noted bilaterally. B. AP pelvis of the same patient demonstrates grade 3 sacroiliitis on the right (circle), meeting the modified New York criteria. Significant hip dysplasia is also noted bilaterally. C. Erosions are noted on the left SI joint (arrow) as well as early ankylosis of the right joint. SI: sacroiliac; CT: computed tomography; AP: anteroposterior. 